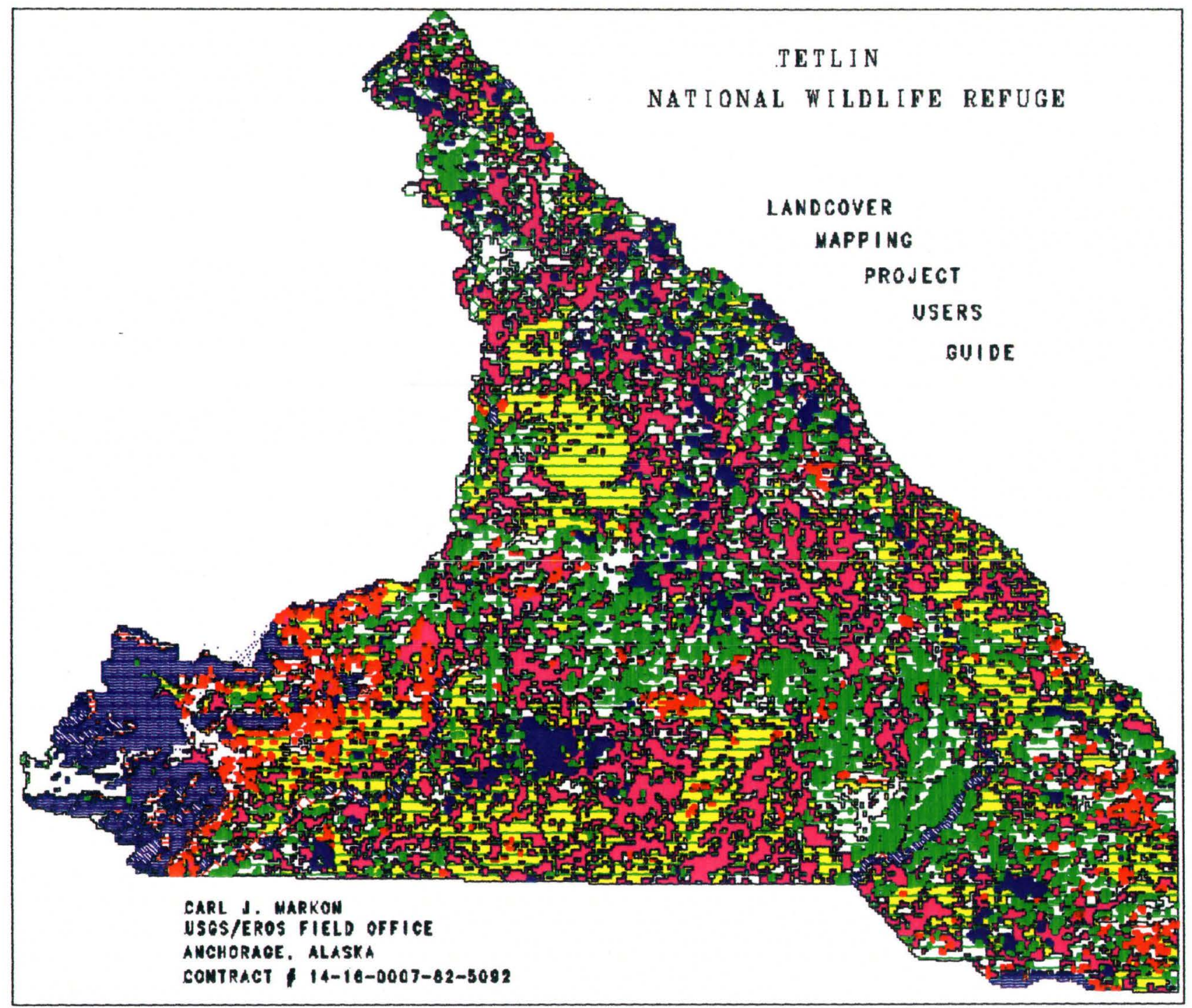




\section{TETLIN NATIONAL WILDLIFE REFUGE \\ LAND COVER MAPPING PROJECT \\ USERS GUIDE}

\section{INTRODUCTION}

Title III of the Alaska National Interest Lands Conservation Act of 1980 (ANILCA, 1980) established the Tetlin National Wildife Refuge (TNWR). Section 304 of the Act requires the Secretary of Interior to "prepare, and from time to time revise, a comprehensive conservation plan" for the refuge. Before developing a plan for the refuge, the secretary shall identify and describe--a) the populations and habitats of the fish and wildife resources of the refuge; b) the special values of the refuge as well as any other archeological, cultural, ecological, geological, historical, palentological, scenic, or wilderness value of the refuge; c) areas within the refuge that are suitable for use as administrative sites or visitor facilities...; d) present the potential requirements for access with respect to the refuge...; and e) significant problems which may adversely affect the populations and habitats of fish and wildife identified and described..." (ANILCA, 1980). Vegetation, water, and terrain (elevation, slope, and aspect) are the components of habitat and can be used in the determination of the above requirements.

The U. S. Fish \& Wildiife Service (USFWS) has the responsibility for collecting the resource information to address the research, management, development and planning requirements identified in Section 304. Because of the brief period provided by the Act for data collection, habitat mapping, and habitat assessment, the USFWS in cooperation with the U.S. Geological Survey's EROS Field Office, used digital Landsat multispectral scanner data (MSS) and digital terrain data to produce land cover and terrain maps. A computer assisted digital analysis of Landsat MSS data was used because coverage by aerial photographs was incomplete for much of the refuge and because the level of detail, obtained from the analysis of Landsat data, is adequate to meet most USFWS research, management and planning needs. Relative cost and time requirements were also factors in the decision to use the digital analysis approach. 


\section{OBJECTIVES}

The primary objectives of the mapping project were to:

1) produce digital land cover/terrain classifications for the TNWR, using digital Landsat and terrain data.

2) provide registered Landsat data for the entire study area defined as the TNWR.

3) provide other derivative products and output products as required.

The primary objectives of this user guide are to give a brief discussion of the methodology used and describe the different types of data products produced.

\section{AREAS OF COVERAGE}

The TNWR consists of approximately 900 thousand acres of land and water in the east central portion of Alaska. The northwest and southeast latitude/longitude coordinates of the mapped area are $6320^{\prime} / 14315^{\prime}$ and $6220^{\prime} / 14045^{\prime}$ respectively. The entire study area covers roughly 1 degree of latitude and 4 degrees of longitude. Portions of one Landsat scene (Number 2958-19453,6 September 1977) provided complete coverage of TNWR and the surrounding area.

\section{METHODOLOGY}

A computer compatible tape (CCT) was obtained for the Landsat scene covering the refuge lands. The Landsat scene was radiometrically and geometrically corrected (registered to a 50-meter Universal Transverse Mercator [UTM] grid) and the boundaries of the refuge and the corresponding 1:63,360-scale USGS quadrangles digitized. This made it possible to summarize land cover information for each quadrangle and the refuge as a whole. Training blocks (sample areas containing representative land cover types) were selected for field study, and training statistics were derived from them. Figure 1 shows the location of the training blocks used in this study. A modified clustering technique was used to generate initial spectral classifications (Fleming, 1975), using the EROS Field Office computer system (HP-3000) and IDIMS software (ESL Incorporated, $1981)$. 


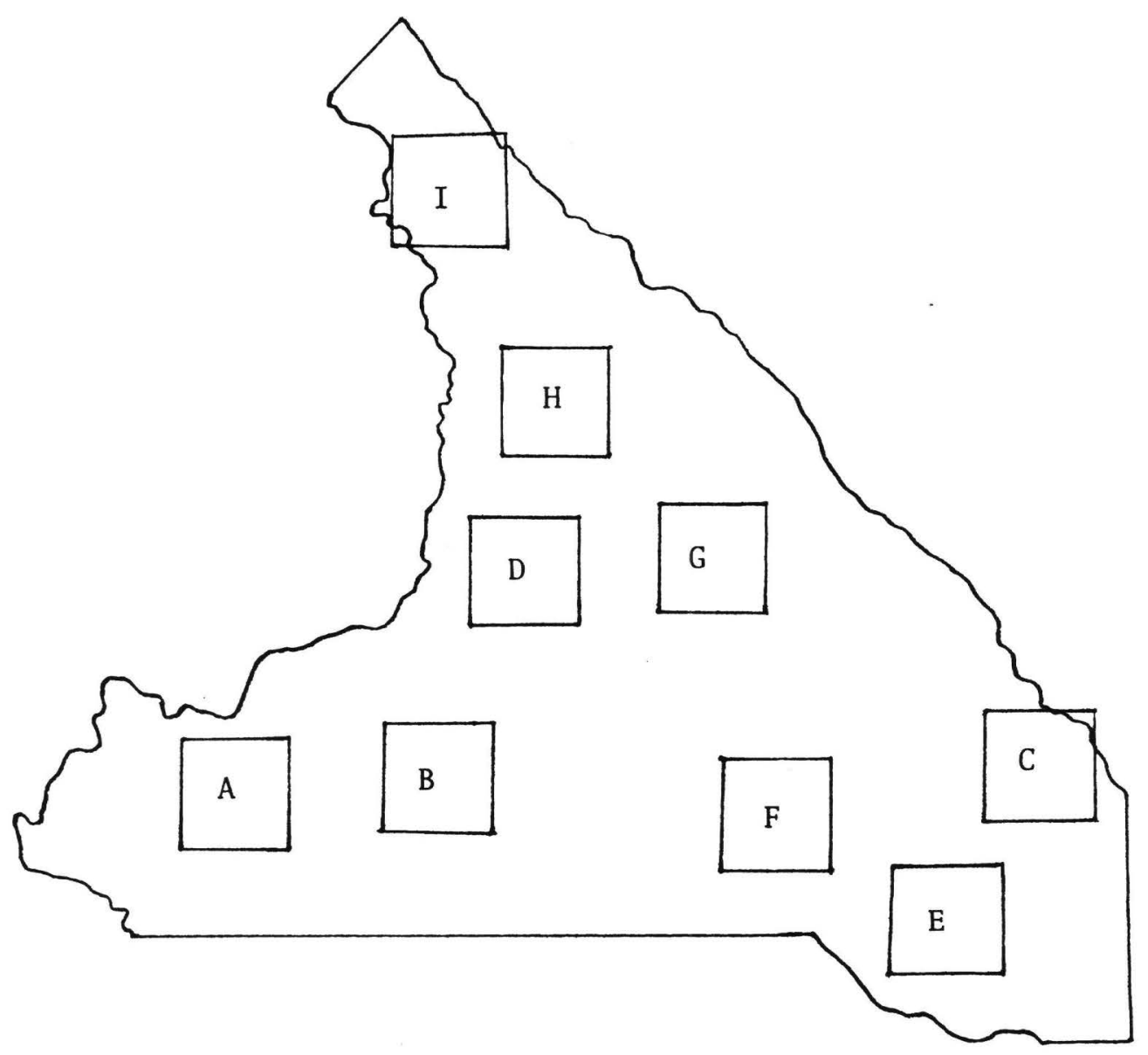

Figure 1.--Location of training blocks used to collect field data and develop training statistics for Landsat scene classification of the Tetlin National Wildlife Refuge. 
Field data on vegetation cover, structure, and composition were collected in each training block to identify land cover types corresponding to computer-derived spectral classes. Final land cover classifications, designated by USFWS personnel, were produced after applying stratification techniques to improve classification accuracy. Land cover classifications were merged with digital terrain data derived from 1:250,000-scale USGS quadrangles to improve classification accuracy and to make possible the production of additional resource data products displaying topographic variables such as elevation, slope, and aspect, either singularly or in combination. The specific procedures used in producing land cover/terrain classifications and output products are detailed in Appendix A. A schematic diagram of the maping process is shown in Figure 2 .

USFWS personnel worked with EROS personnel to conduct the digital analysis required to produce land cover classifications for the refuge and coordinated with USFWS.Information Resource Management personnel to ensure that the digital data were compatible with the USFWS geobased information system.

\section{PRODUCTS}

The following products were produced for the mapping project:

1) Land cover classifications of the refuge and surrounding areas. This included hard copy $1: 250,000$ photographic prints of the land cover.

2) Acreage estimates for each land cover type in the refuge for each 1:63,000-scale USGS quadrangle and for the refuge as a whole.

3) Computer tapes of all raw and registered Landsat scenes.

4) Computer tapes containing land cover and terrain data classifications.

5) Computer tapes of resampled land cover and terrain data.

6) Elevation, slope, and aspect maps in the form of photographic prints at a 1:250,000 scale.

7) This users guide. 


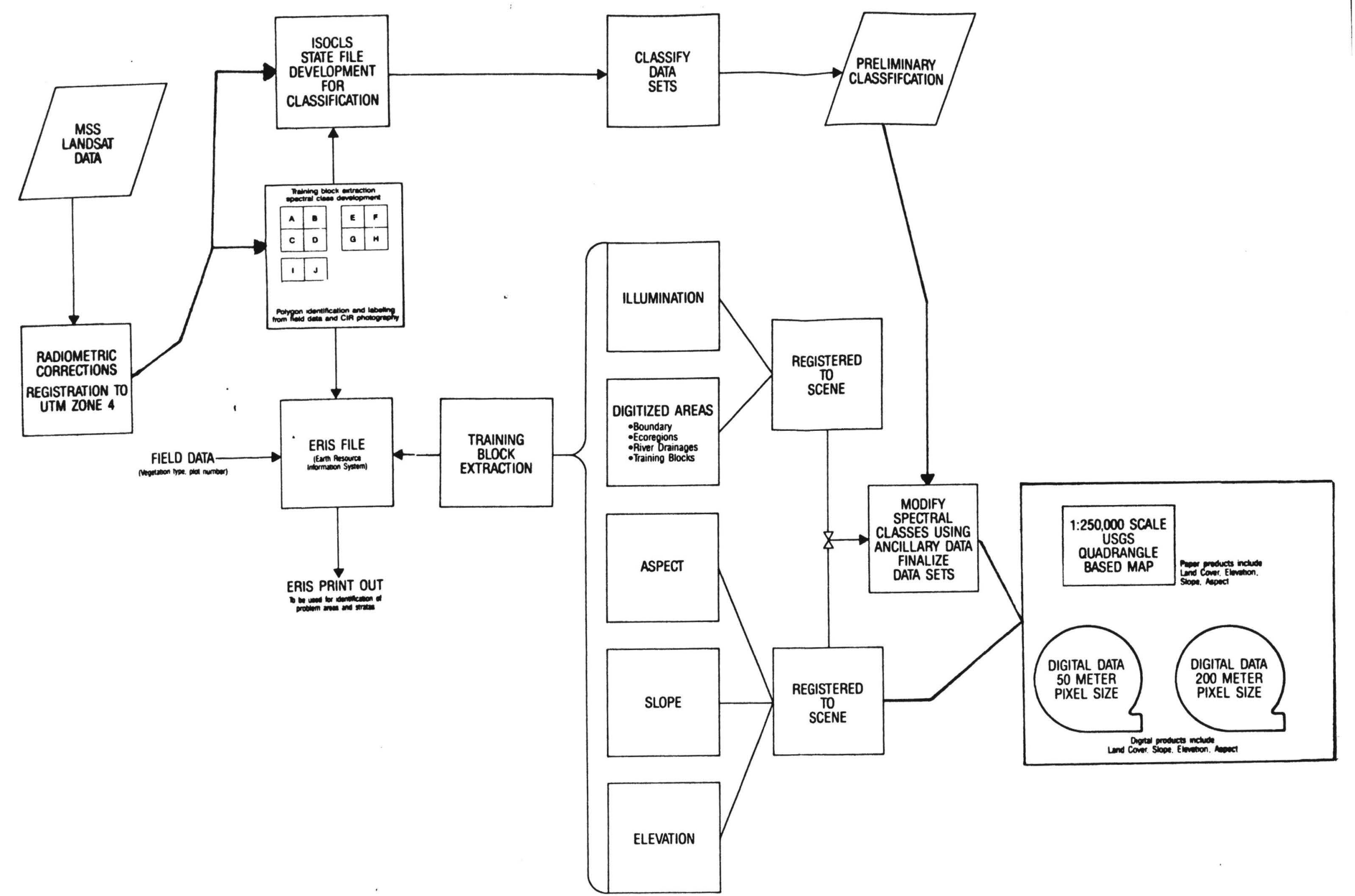

Figure 2.--Schematic diagram of the mapping process used to produce the 


\section{PRODUCT DESCRIPTIONS-HARD COPY}

\section{LAND COVER CLASS DESCRIPTIONS}

Based on information acquired in the field, discussions with USFWS personnel, and Landsat spectral discrimination, seven major land cover classes were recognized: Forest, Deciduous, Scrub, Dwarf Scrub, Herbaceous, Scarcely Vegetated, Water, and Snow. Included in these major classes are 19 subclasses (Table 1). A complete description of each of the major classes and subclasses can be found in Talbot et al. (1984).

Acreage estimates for each land cover class within the refuge were summarized and are 1isted in Table 2. Acreage estimates for each class summarized by $1: 63,360$ USGS quadrangle covering the TNWR are listed in Appendix B.

Final hard copy land cover maps were produced at a $1: 250,000$ scale in the form of a photographic print. Each map contained collar information which included: map title, a list of vegetation classes, locational diagram of the refuge with respect to the state, scale bar and latitude/longitude tick marks. Each land cover class was depicted on the map as a color. The color scheme used was based on input from USFWS and USGS/EROS personnel.

\section{TERRAIN CLASS DESCRIPTIONS}

Terrain class maps were produced from the elevation, slope, and aspect digital data and produced for the refuge. Elevation classes were broken into the following catagories (in meters): 489-548, 549-610, 611-731, 732-853, 854-975, 976-1066, 1067-1219, 1220-1371, 1372-1524, 1525-1676, 1677-1981, 1982-2255, 2256 and higher. Slope classes were broken into $0-2 \%, 3-5 \%, 6-10 \%, 11-15 \%, 16-25 \%, 26-40 \%, 41-70 \%$, and $71 \%$ and higher. The aspect classes were broken into eight directions: north, northeast, east, southeast, south, southwest, west, northwest. All of the maps contained the water classes and the aspect map contained the $0-2 \%$ slope class. Collar information included: map title, scale, locational diagram, map legend, latitude/longitude, and tick marks.

\section{OTHER PRODUCTS}

Photographic products of the land cover and terrain maps may be purchased from USGS/EROS. 
Table 1.--Land cover classes used for the Tetlin National Wildife Refuge land cover map.

CLASS VALUE

0,1 2

3

4

5

6

7

8

9,12

10

11,21

13

14

15

16

17

18

19

20

22

\section{CLASS DESCRIPTION}

Background

Closed Needleleaf Forest

Open Needleleaf Forest

Needleleaf Woodland

Mixed Forest

Deciduous Forest

Lowland Deciduous Scrub

Alpine and Subalpine Deciduous Scrub

Graminoid Marsh/Alluvial Scrub

Prostrate Shrub Tundra

Dwarf Shrub Graminoid Tussock Peatland

Clear Water

Shallow-Low Sedimented Water

Aquatic Vegetation

Medium-High Sedimented Water

Barren Screes

Scarcely Vegetated Screes

Barren Floodplain

Scarcely Vegetated Floodplain

Snow

Northway Airport 
Table 2.--Acreage estimates for each land cover class for the Tetiln National Wildlife Refuge.

ACRES $\quad$ PERCENT

Closed Needleleaf Forest

89799.7

$9.70 \%$

Open Needleleaf Forest

$197923.5 \quad 21.39 \%$

Needleleaf Woodland

$264049.9 \quad 28.54 \%$

Mixed Forest

31974.8

$3.46 \%$

Deciduous Forest

16186.3

$1.75 \%$

Lowland Deciduous Scrub

6199.9

$0.67 \%$

Alpine and Subalpine Deciduous Scrub

37029.4

$4.00 \%$

Graminoid Marsh/Alluvial Scrub

2934.6

$0.32 \%$

Prostrate Shrub Tundra

4380.2

$0.47 \%$

Dwarf Shrub Graminoid Tussock Peatland

190285.6

$20.56 \%$

Graminoid Marsh/Alluvial Scrub

$12955.6 \quad 1.40 \%$

Clear Water

28940.4

$3.13 \%$

Shallow Low Sedimented Water/Aquatic Veg.

8737.1

$0.94 \%$

Medium-High Sedimented Water

6403.0

$0.69 \%$

Barren Screes

11053.2

$1.19 \%$

Scarcely Vegetated Screes

3273.4

$0.35 \%$

Barren Floodplain

4606.8

$0.50 \%$

Scarcely Vegetated Floodplain

7831.3

$0.85 \%$

Sn ow

691.2

$0.07 \%$

Northway Airport

$68 \cdot 5$

$0.01 \%$

TOTALS

$925324.4 \quad 100.00 \%$ 


\section{PRODUCT DESCRIPTIONS-DIGITAL}

\section{GENERAL}

Digital data are stored at USGS/EROS on CCT's in either an IDTRANS or TRANSFER format. Digital data stored in the IDTRANS format are used at USGS/EROS for internal processing. The TRANSFER format is usually used when data are shipped to other U.S. government agencies or the private sector. Images are generally written on a TRANSFER tape with one image line per record and one image per file. Images may be band-by-band or line-by-line. If the data format is floating point, either a Hewlett-Packard 3000 or IBM format may be specified. Data may be read onto the tape at either 1600 or 6250 bits/inch (bpi). All data relating to this project have been delivered to USFWS at 1600 bpi using the Hewlett-Packard 3000 floating point format.

An attempt was made to standardize the pixel size and UTM origins of the data. For this project the final data sets were produced at three different pixel sizes: $50 \times 50$ meter, $100 \times 100$ meter, and 200X200 meter. Pixel sizes were predetermined by the USFWS prior to the finalization of the land cover classification. All of the data which has been transfered to the USFWS covered under the Interagency Service Agreement is summarized in Appendix C. This summarization contains image name, data type, number of lines and samples, UTM origins, pixel size, and storage location at the EROS Field office.

\section{LAND COVER}

The land cover images contain up to 19 different classes (Table 1). The data is byte data. The lowest class, 0 , is a background or fill class. The class descriptions corresponding to each class number may be found in Talbot et al. 1984.

\section{ELEVATION DATA}

The digital elevation data were derived from digital terrain data created by the Defense Mapping Agency (DMA). The DMA generated the data by digitizing contour lines, spot elevations, and stream and ridge line data from the 1:250,000-scale USGS quadrangles. The contour intervals range from 50 to 200 feet. These data were then converted to a rectangular grid of values, producing elevation estimates spaced every 0.01 inches on each $1: 250,000-$ scale map (approximately 200 feet on the ground). The data are integer data and can range in values from 0 to about 3000 meters. The data is recorded in one meter increments. 


\section{SLOPE DATA}

The slope data were computed using the digital elevation data. Slope is computed as percent slope, 1.e. units of rise per 100 units of run. The data is byte data and is recorded in one percent increments. Values can range from 0 to 255 .

\section{ASPECT DATA}

The aspect data were computed using the digital elevation data. Aspect is computed clockwise from north in degrees. The data are byte data with values from 0 to $180: 0$ and $180=$ north, east $=45$, south $=90$, and west $=135$. Values increase in two degree increments. 


\section{ACKNOWLEDGEMENTS}

This project was funded by an interagency service agreement between the U.S. Fish and Wildilfe Service and the U.S. Geological Survey/EROS Anchorage Field office, contract number 14-16-0007-82-5092. Field and botanical assistance was provided by Steve Talbot and Mark Shasby. Appreciated are David Carneggie and Mark Shasby for their support and review of this report.

\section{REFERENCES}

ANILCA, 1980. Alaska National Interest Lands Conservation Act, Public Law 96-487, Washington, D.C.

ESL Incorporated, 1981. IDIMS Functional Guide, Technical Manual ESL-TM705. ESL Incorporated, Sunnyvale, California. Vol. I, 716 p., Vol. II, 319 p.

Fleming, M. D., 1975, Computer aided analysis of Landsat data: a comparison of three approaches including modified clustering approach: West Lafayette, Indiana, Purdue University Laboratory for Applications of Remote Sensing, LARS Information Note 072475,9 p.

Talbot, S. S., Markon, C. J., and Shasby, M. B., 1984, Landsat facilitated vegetation classification of Tetiin National Wildife Refuge, Alaska, in Inventorying Forest and 0 ther Vegetation of the High Latitude and High Altitude Regions, Fairbanks, Alaska, 1984, Proceedings: Washington, D.C., Society of American Foresters, p. 143-151. 


\section{APPENDIX A}

PROCEDURES FOR LAND COVER CLASSIFICATION USING LANDSAT CCT'S

\section{Preprocessing}

1. Enter Landsat Data (CCT format) into IDIMS

2. Display and select Landsat subscenes

3. Perform radiometric corrections

a. Destrip to correct for detector miscalibration

b. Fix bad data lines

4. Perform geometric corrections

a. Select control points from Landsat data and maps for image registration

b. Digitize control points and map boundaries

c. Generate transformations and rotate Landsat scenes

d. Register Landsat image to 50 meter UTM grid

5. Produce strata mask for study areas

6. Digitize refuge boundaries

7. Mosaic and register DEM data

Image Training and Classification

1. Select training blocks for study area in each Landsat scene

2. Apply IDIMS clustering algorithm (ISOCLAS)

3. Produce statistics of the spectral classes within the training blocks

4. Produce photographic image of each Landsat training block and color coded cluster map

5. Prepare for field investigations

a Acquire aerial photographs of cluster blocks for annotation in field

b. Develop strategy for aerial reconnaissance and on-the-ground investigations 


\section{APPENDIX A}

6. Field verification

a. Describe land cover type associated with each cluster class

b. Collect auxiliary information when appropriate, e.g. wildife habitat value, soils, quantitative plant description, etc.

7. Return to IDIMS and edit cluster statistics and pool and/or delete cluster classes

8. Produce preliminary classification based on edited cluster statistics

9. Evaluate preliminary classification based on edited cluster statistics

10. Post-classification refinement where necessary to improve classification accuracy. This step may be facilitated by several approaches, two of which are presented:

a Stratification based upon physiognomic, soil or other resource data

(1) Digitize boundaries of strata

(2) Produce and apply strata mask

(3) Identify cluster classes for each strata

(4) Combine classifications for all strata

(5) Reclassify entire study area

b. Merge DEM digital terrain data with Landsat data

(1) Define control points for DEM

(2) Generate transformation between

latitude/longitude (DEM) and UTM grid

(3) Register DEM to UTM grid

(4) Generate slope and aspect data

(5) Define strata based on combinations of elevation, slope, and aspect

(6) Identify cluster classes within each strata 


\section{APPENDIX A}

\section{Generate Output Products}

1. Generate digital tape file for classification of refuge ( $1: 250,000$ USGS quadrangles)

2. Generate digital tape files for classification of the refuge matching the $1: 63,360-$ scale USGS quadrangles

3. Produce acreage estimate for refuge or units (quadrangles) within refuge area

4. Produce photographic prints for the final classification of the refuge area at a $1: 250,000$ scale 
APPENDIX B

CLOSED NEEDLELEAF FOREST

OPEN NEEDLELEAF FOREST

NEEDLELEAF WOODLAND

MIXED FOREST

DECIDUOUS FOREST

LOWLAND DECIDUOUS SCRUB

ALPINE AND SUBALPINE DECIDUOUS SCRUB

GRAMINOID MARSH/ALLUVIAL SCRUB

PROSTRATE SHRUB TUNDRA

DWARP SHRUB GRAMINOID TUSSOCK PEATLAND

GRAMINOID MARSH/ALLUVIAL SCRUB

CLEAR WATER

SHALLOW LOW SEDIMENTED WATER/AQUATIC VEG.

MEDIUM-HIGH SEDIMENTED WATER

BARREN SCREES

SCREES

BARREN FLOODPLAI

SCARCELY VEGETATED FLOODPLAIN

SNOW

NORTHWAY AIRPORT

TOTAL

\begin{tabular}{|c|c|c|c|c|c|c|c|c|c|}
\hline \multicolumn{2}{|c|}{$\begin{array}{c}\text { NABESNA } \\
\mathrm{C}-4\end{array}$} & \multicolumn{2}{|c|}{$\begin{array}{c}\text { NABESNA } \\
\mathrm{C}-3\end{array}$} & \multicolumn{2}{|c|}{$\begin{array}{c}\text { NABESNA } \\
\mathrm{C}-2\end{array}$} & \multicolumn{2}{|c|}{$\begin{array}{c}\text { NABESNA } \\
\mathrm{C}-1\end{array}$} & \multicolumn{2}{|c|}{$\begin{array}{c}\text { NABESNA } \\
\text { D-3 }\end{array}$} \\
\hline ACRES & PERCENT & ACRES & PERCENT & ACRES & PERCENT & ACRES & PERCENT & ACRES & PERCENT \\
\hline 1687.0 & 2.3 & 10499.8 & 6.4 & 20013.8 & 11.9 & 26653.3 & 17.1 & 5181.6 & 8.7 \\
\hline 2681.6 & 3.6 & 25786.6 & 15.8 & 43108.9 & 25.5 & 39081.8 & 25.1 & 14694.3 & 24.6 \\
\hline 4169.1 & 5.6 & 45206.2 & 27.6 & 61365.2 & 36.4 & 40086.9 & 25.8 & 18462.6 & 30.9 \\
\hline 3551.4 & 4.8 & 12431.5 & 7.6 & 3562.5 & 2.1 & 6436.3 & 4.1 & 1373.2 & 2.3 \\
\hline 2747.1 & 3.7 & 5998.3 & 3.7 & 1178.0 & 0.7 & 3006.5 & 1.9 & 155.0 & 0.3 \\
\hline 940.8 & 1.3 & 1595.6 & 1.0 & 428.7 & 0.3 & 315.6 & 0.2 & 101.9 & 0.2 \\
\hline 31169.7 & 42.3 & 4136.4 & 2.5 & 84.6 & 0.1 & 89.5 & 0.1 & 42.6 & 0.1 \\
\hline 35.8 & 0.0 & 620.2 & 0.4 & 98.8 & 0.1 & 116.1 & 0.1 & 680.1 & 1.1 \\
\hline 4356.9 & 5.9 & 8.6 & 0.0 & 0.0 & 0.0 & 0.0 & 0.0 & 0.0 & 0.0 \\
\hline 6078.0 & 8.3 & 44560.6 & 27.2 & 34134.3 & 20.2 & 32085.2 & 20.6 & 15401.0 & 25.8 \\
\hline 156.9 & 0.2 & 690.6 & 0.4 & 447.2 & 0.3 & 843.8 & 0.5 & 543.6 & 0.9 \\
\hline 32.7 & 0.0 & 5379.9 & 3.3 & 3089.3 & 1.7 & 2243.0 & 1. & 415.7 & 0.7 \\
\hline 11.7 & 0.0 & 581.3 & 0.4 & 693.1 & 0.4 & 576.3 & 0.4 & 753.0 & 1.3 \\
\hline 532.4 & 0.7 & 2387.5 & & & 0.0 & 1111.9 & 0 . & 429.9 & 0.7 \\
\hline 10974.9 & 14.8 & 56.8 & 0 . & 4.3 & 0. & 8.0 & 0 . & 1.8 & 0.0 \\
\hline 3251.8 & 4.4 & 14.2 & 0. & 0.0 & 0. & 0.0 & 0.0 & 0.0 & 0.0 \\
\hline 252.0 & 0.4 & 1575.8 & 1.0 & 59.9 & 0.0 & 909.3 & 0.6 & 364.4 & 0.6 \\
\hline 594.2 & 0.8 & 2117.6 & 1. & 431.1 & 0 . & 1858.1 & 1.2 & $105+3.2$ & 1.8 \\
\hline 690.6 & 0.9 & 0.6 & 0.0 & 0.0 & 0.0 & 0.0 & 0.0 & 0.0 & 0.0 \\
\hline 0.0 & 0.0 & 0.0 & 0.0 & 0.0 & 0.0 & 0.0 & 0.0 & 0.0 & 0.0 \\
\hline 3914.6 & 100.0 & 3648.1 & 100.0 & 8774.4 & 100.0 & 5421.6 & 99.9 & 59653.9 & 00 . \\
\hline
\end{tabular}


APPENDIX B

CLOSED NEEDLELEAF FOREST

OPEN NEEDLELEAF FOREST

NEEDLELEAF WOODLAND

MIXED POREST

ROREST

OWLAND DECIDUOUS SCRUB

ALPINE AND SUBALPINE DECIDUOUS SCRUB

GRAMINOID MARSH/ALLUVIAL SCRUB

PROSTRATE SHRUB TUNDRA

DWARF SHRUB GRAMINOID TUSSOCK PEATLAND

GRAMINOID MARSH/ALLUVIAL SCRUB

CLEAR WATER

SHALLOW LOW SEDIMENTED WATER/AQUATIC VEG.

MEDIUM-HIGH SEDIMENTED WATER

BARREN SCREES

SCARCRLY VECETATED SCREES

BARREN FLOODPLAIN

SCARCELY VEGETATED FLOODPLAIN

SNOW

NORTHWAY AIRPORT

TOTAL

\begin{tabular}{|c|c|c|c|c|c|c|c|c|c|c|c|}
\hline \multicolumn{2}{|c|}{$\begin{array}{c}\text { NABESNA } \\
\text { D-2 }\end{array}$} & \multicolumn{2}{|c|}{$\begin{array}{c}\text { NABESNA } \\
\text { D-1 }\end{array}$} & \multicolumn{2}{|c|}{$\begin{array}{c}\text { NABESNA } \\
\text { B-2 }\end{array}$} & \multicolumn{2}{|c|}{$\begin{array}{c}\text { NABESNA } \\
\text { B-1 }\end{array}$} & \multicolumn{2}{|c|}{$\begin{array}{c}\text { TANACROSS } \\
\text { A-3 }\end{array}$} & \multicolumn{2}{|c|}{$\begin{array}{c}\text { TANACROSS } \\
\text { A-2 }\end{array}$} \\
\hline ACRES & PERCENT & ACRES & PERCENT & ACRES & PERCENT & ACRES & PERCENT & ACRES & PERCENT & ACRES & PERCENT \\
\hline 15288.6 & 9.6 & 1007.5 & 3.8 & 0.6 & 14.3 & 3531.6 & 8.4 & 4507.7 & 7.8 & 1428.2 & 8.2 \\
\hline 40120.2 & 25.1 & 3844.2 & 14.6 & 2.4 & 57.1 & 10967.5 & 25.8 & 13699.8 & 23.6 & 3936.2 & 22.6 \\
\hline 49723.1 & 31.1 & 10181.1 & 38.8 & 1.2 & 28.6 & 13456.4 & 31.8 & 16598.9 & 28.7 & 4799.2 & 27.4 \\
\hline 693.1 & 0.4 & 194.5 & 0.7 & 0.0 & 0.0 & 3327.8 & 7.8 & 373.7 & 0.6 & 30.8 & 0.2 \\
\hline 1596.8 & 1.0 & 89.5 & 0.3 & 0.0 & 0.0 & 1291.7 & 3.0 & 67.9 & 0.1 & 55.5 & 0.3 \\
\hline 1845.2 & 1.2 & 53.7 & 0.2 & 0.0 & 0.0 & 264.3 & 0.6 & 491.1 & 0.8 & 163.0 & 0.9 \\
\hline 0.0 & 0.0 & 0.0 & 0.0 & 0.0 & 0.0 & 1506.6 & 3.5 & 0.0 & 0.0 & 0.0 & 0.0 \\
\hline 1212.0 & 0.8 & 0.0 & 0.0 & 0.0 & 0.0 & 0.0 & 0.0 & 1.8 & 0.0 & 169.8 & 1.0 \\
\hline 1.8 & 0.0 & 0.0 & 0.0 & 0.0 & 0.0 & 12.9 & 0.0 & 0.0 & 0.0 & 0.0 & 0.0 \\
\hline 27790.6 & 17.4 & 9651.0 & 36.8 & 0.0 & 0.0 & 6894.6 & 16.2 & 11124.3 & 19.2 & 2566.0 & 14.6 \\
\hline 4290.8 & 2.6 & 173.5 & 0.7 & 0.0 & 0.0 & 24.7 & 0.1 & 4203.7 & 7.3 & 1580.8 & 9.0 \\
\hline 10989.1 & 6.9 & 331.7 & 1.3 & 0.0 & 0.0 & 1010.0 & 2.4 & 4099.3 & 7.1 & 1349.7 & 7.7 \\
\hline 3610.1 & 2.3 & 155.0 & 0.6 & 0.0 & 0.0 & 174.8 & 0.4 & 1517.8 & 2.6 & 664.0 & 3.7 \\
\hline 1380.6 & 0.9 & 367.5 & 1.4 & 0.0 & 0.0 & 0.0 & 0.0 & 72.2 & 0.1 & 46.3 & 0.3 \\
\hline 0.0 & 0 & 0.0 & 0.0 & 0.0 & 0.0 & 7.4 & 0.0 & 0.0 & 0.0 & 0.0 & 0.0 \\
\hline 0.0 & 0.0 & 0.0 & 0.0 & 0.0 & 0.0 & 7.4 & 0.0 & 0.0 & 0.0 & 0.0 & 0.0 \\
\hline 488.0 & 0.3 & 129.7 & 0.5 & 0.0 & 0.0 & 0.0 & 0.0 & 435.5 & 0.8 & 392.2 & 2.2 \\
\hline 627.6 & 0.4 & 72.8 & 0.3 & 0.0 & 0.0 & 0.0 & 0.0 & 738.8 & 1.3 & $1 \quad 337.9$ & 1.9 \\
\hline 0.0 & 0.0 & 0.0 & 0.0 & 0.0 & 0.0 & 0.0 & 0.0 & 0.0 & 0.0 & 0.0 & 0.0 \\
\hline 68.5 & 0.0 & 0.0 & 0.0 & 0.0 & 0.0 & 0.0 & 0.0 & 0.0 & 0.0 & 0.0 & 0.0 \\
\hline 726.1 & 100.0 & 26251.7 & 100.0 & 4.2 & 100.0 & 42477.7 & 100.0 & 57932.5 & 100.0 & 17519.6 & 100.0 \\
\hline
\end{tabular}




\section{APPENDIX C}

The following source data is relevant to all images listed below. Coverage: Registered MSS data for TNWR

$\begin{array}{llll}\text { UTM Northing } & =7040000 & \text { Number of Lines } & =2800 \\ \text { UTM Easting } & =380000 & \text { Number of Samples } & =2600 \\ \text { UTM Zone } & =7 & \text { Pixel Size (in meters) } & =50 \\ & & \text { Tape Format } & =\text { IDTRANS }\end{array}$

\begin{tabular}{|c|c|c|c|}
\hline $\begin{array}{l}\text { TYPE OF } \\
\text { IMAGE } \\
\end{array}$ & $\begin{array}{l}\text { DATA } \\
\text { TYPE } \\
\end{array}$ & $\begin{array}{l}\text { EROS FIELD OFFICE } \\
\text { TAPE LOCATION } \\
\end{array}$ & $\underline{\text { F ILE }}$ \\
\hline Landcover & Byte & 1008 & 11 \\
\hline Elevation & Integer & & \\
\hline Slope & Byte & & \\
\hline Aspect & Byte & & \\
\hline
\end{tabular}

The following source data is relevant to all images 1 isted below. Coverage: Preliminary classification of TNWR

$\begin{array}{llll}\text { UTM Northing } & =7040000 & \text { Number of Lines } & =2800 \\ \text { UTM Easting } & =380000 & \text { Number of Samples } & =2600 \\ \text { UTM Zone } & =7 & \text { Pixel Size (in meters) } & =50 \\ & & \text { Tape Format } & =\text { IDTRANS }\end{array}$

$\begin{array}{llcr}\text { TYPE OF } & \text { DATA } & \text { EROS FIELD OFFICE } & \\ \text { IMAGE } & \text { TYPE } & \text { TAPE LOCATION } & \text { FILE } \\ \text { Landcover } & \text { Byte } & 1010 & 6 \\ \text { Elevation } & \text { Integer } & & \\ \text { Slope } & \text { Byte } & & \\ \text { Aspect } & \text { Integer } & & \end{array}$




\section{APPENDIX C}

The following source data is relevant to all images listed below. Coverage: Tetlin NWR

$\begin{array}{llll}\text { UTM Northing } & =7010250 & \text { Number of Lines } & =1800 \\ \text { UTM Easting } & =402850 & \text { Number of Samples } & =1946 \\ \text { UTM Zone } & =7 & \text { Pixel Size (in meters) } & =50 \\ & & \text { Tape Format } & =\text { IDTRANS }\end{array}$

\begin{tabular}{llcr} 
TYPE OF & DATA & EROS FIELD OFFICE \\
IMAGE & TYPE & TAPE LOCATION & FILE \\
\cline { 3 - 5 } $\begin{array}{l}\text { Landcover } \\
\text { Elevation }\end{array}$ & Byte & 1003 & 1 \\
Slope & Integer & 1003 & 3 \\
Aspect & Byte & 1003 & 4 \\
Refuge Mask & Byte & 1003 & 5 \\
& Byte & 1003 & 2
\end{tabular}

The following source data is relevant to all images 1 isted below. Coverage: Tet 1 in NWR

$\begin{array}{llll}\text { UTM Northing } & =7010250 & \text { Number of Lines } & =354 \\ \text { UTM Easting } & =402850 & \text { Number of Samples } & =384 \\ \text { UTM Zone } & =7 & \text { Pixel Size (in meters) } & =254 \\ & & \text { Tape Format } & =\text { IDTRANS }\end{array}$

\begin{tabular}{llcr} 
TYPE OF & DATA & EROS FIELD OFFICE \\
IMAGE & TYPE & TAPE LOCATION & FILE \\
\cline { 3 - 4 } & Byte & 1003 & 6 \\
Elevation & Integer & 1003 & 8 \\
S1ope & Byte & 1003 & 10 \\
Aspect & Byte & 1003 & 9 \\
Refuge Mask & Byte & 1003 & 7
\end{tabular}




\section{APPENDIX C}

The following data files contain land cover classification and correspond to the USGS 15 minute $(1: 63,360$ scale) topographic maps covering the TNWR. All of the data can be found on EROS Anchorage Field Office storage tape IDT 1006 :

$\begin{array}{lc}\text { QUADRANGLE } & \text { FILE NO. } \\ \text { Tanacross A3 } & 2 \\ \text { Tanacross A2 } & 3 \\ \text { Nabesna D } 3 & 4 \\ \text { Nabesna D } 2 & 5 \\ \text { Nabesna D } 1 & 6 \\ \text { Nabesna C } 4 & 7 \\ \text { Nabesna C } 3 & 8 \\ \text { Nabesna C } 2 & 9 \\ \text { Nabesna C } 1 & 10 \\ \text { Nabesna B } 2 & 11 \\ \text { Nabesna B } 1 & 12\end{array}$

